JESTT Vol. 2 No. 8 Agustus 2015

\title{
GADAI EMAS ALTERNATIF TAMBAHAN MODAL USAHA MIKRO KECIL DAN MENENGAH PADA LEMBAGA KEUANGAN SYARIAH')
}

\author{
Ninda Ardiani \\ Mahasiswa Program Studi S1 Ekonomi Islam-Fakultas Ekonomi dan Bisnis-Universitas Airlangga \\ Email : ardianinda@gmail.com \\ Muhamad Nafik H.R. \\ Departemen Ekonomi Syariah-Fakultas Ekonomi dan Bisnis-Unversitas Airlangga \\ Email : manhard999@yahoo.com
}

\begin{abstract}
:
The method used is a qualitative approach with the strategy case study. The collection of data that is passed is the interview to the informant, the assistant pawn Islamic financial institutions and Micro, Small and Medium Enterprises customers pawn gold,. The analysis technique used is the technique of pairing patterns with narrating the interviews with informants. Results from this study is the gold pawn Islamic financial institutions may be a reinforcement of capital Micro, Small and Medium Enterprises. The use of gold as a pledge of capital strengthening of capital Micro, Small and Medium Enterprises undertaken to meet short-term capital in the form of working capital. Requirements are simple and fast process makes this product desirable pengusha Micro, Small and Medium Enterprises. Using gold as a pledge of additional capital, the of capital Micro, Small and Medium Enterprises business grew and developing States.
\end{abstract}

\section{Keywords: Gold Pawn, Modal, Micro, Small and Medium Enterprise.}

\section{PENDAHULUAN}

UMKM memiliki peran penting dalam perkembangan dan pertumbuhan ekonomi suatu negara. Kebnyakan UMKM menggunakan dana pribadi untuk mengembangakn usahanya. Skim kredit yang sudah diberikan oleh Lembaga Keuangan untuk UMKM tidak dapat sepenuhnya dimanfaatkan UMKM. Prosedur penyaluran dana dari lembaga keuangan bank ataupun non-bank yang rumit dan membutuhkan waktu yang lama. Pengusaha UMKM mencari alternatif modal untuk mengembangkan usahanya. Keterbatasan Modal usaha UMKM merupakan kendala terbesar dalam perkembangan UMKM

\begin{abstract}
Bank syariah adalah lembaga keuangan yang usaha pokoknya memberikan pembiayaan dan jasa jasa lainnya dalam prinsip syariah Islam (Muhammad:2002) . Penyaluran dana dari
\end{abstract} Bank Syariah dengan pembiayaan dengan prinsip jual beli, sewa dan bagi hasil dapat dimanfaatkan untuk pemberian modal untuk perkembangan UMKM. Baitul maal wat tamwil yang merupakan salah satu lembaga keunangan syariah mikro yang bertujuan untuk menciptakan sumber pembiayaan dan penyedia modal bagi anggota dengan prinsip syariah dapat menjadi rujukan umkm untuk mendapatkan modal.

Gadai emas Lembaga Keuangan Syariah dapat menjadi salah satu

\footnotetext{
1) Jurnal ini merupakan bagian dari skripsi Ninda Ardiani, NIM: 041 114135, yang diuji pada 10 Juli 2015
} 
alternatif yang diberikan lembaga keuangan bank untuk menyalurkan dana untuk permodalan UMKM. Produk gadai emas yang di tawarkan bank syariah dan BMT ini merupakan salah satu pembiayaan dengan akad pelengkap yang ditujukan untuk memperlancar pembiayaan dengan menggunakan gabungan dari prinsip jual beli, sewa dan bagi hasil.

Emas merupakan aset yang likuid sehingga pada saat harga emas murah pengusaha UMKM dapat membeli emas tersebut dan ketika harga emas tinggi dapat menjual emas tersebut untuk tambahan modal usaha mereka. Harga emas yang berlawanan dengan harga dolar dapat menjadikan emas sebagai alternatif untuk berinvestasi.

Penyediaan dana yang relatif cepat dengan syarat yang mudah pada produk gadai emas Bank Syariah dan BMT dapat menjadi alternative pemberiaan modal pada UMKM yang tidak berbadan hukum ataupun berbadan hukum. Keterbatasan modal yang dihadapi UMKM menjadi kendala dalam perkembangan UMKM. Pemberian modal oleh lembaga keuangan yang menuntut persyartan yang rumit dan proses yang lama, sehingga UMKM tidak mudah mendapatkan modal dari lembaga kevangan. Gadai emas Bank Syariah dan BMT sebagai produk penyaluran dana yang ditawarkan dapat dikatakan sebagai alternatif pemberian modal pada UMKM. Keterbatasan modal yang dihadapi oleh UMKM dapat teratasi dengan dengan adanya gadai emas.

\section{TINJAUAN PUSTAKA}

\section{Gadai Syariah}

Ali (2008:3) berpendapat bahwa gadai (rahn) adalah menahan barang jaminan yang bersifat materi milik rahin sebagai jaminan atas pinjaman yang dterimanya, dan barang yang diterima tersebut bernilai ekonomis, sehingga murtahin memperoleh jaminan untuk mengambil kembali seluruh atau sebagian hutangnya dari barang yang di maksud bila pihak yang menggadaikannya tidak dapat membayar hutangnya pada saat jatuh tempo. Anshori (2006:91-9-92) menjelaskan ada berberaa rukun dan syarat sahnya perjanjian gadai sebagai berikut :
a. Ijab Qabul
b. Orang yang bertransaksi
C. Marhun
d. Marhun bih

Pemanfaatan barang gadai bertujuan untuk memelihara keutuhan nilai dai barang gadai. Permasalahnnya adalah pihak mana yang berhak atas pemanfataan barang gadai tersebut (Ali, 2008:31). Menurut Rais (2006:163), pemanfataan marhun bih oleh nasabah pada dasarnya diidentifikasi pada saat calon nasaabh mengajukan pinjaman, berupa untuk keperluan perdagangan, pendidikan, pertanian, perumahan, kesehatan, atau industri, namun hal itu sebatas untuk mengidentifikasi sejak, dan 
tidak berpengharuh pada diterima atau tidaknya calon nasabah tersebut.

Akad dalam transaksi rahn akan berkahir bila terpenuhinya beberapa hal, yaitu (a) barang telah diserahkan kembali kepada pemilknya; (b) rahin membayar hutangnya; (c) Barang gadai dijual dengan perintah hakim atas permintaan murtahin; (d) Pembebasan hutang dengan cara apapun; (e) Pembatalan oleh murtahin, meskipun tidak ada persetujuan dari pihak rahin; (f) Rusaknya barang rahn bukan oleh tindakan/penggunaan murtahin dan (g) Memanfaatkan barang rahn sebagai penyewaan, hibah, atau shadaqah, baik dari pihak rahin maupun murtahin. (Ali, 2008:39).

\section{Usaha Mikro Kecil dan Menengah}

Undang Undang Republik Indonesia Nomor 20 tahun 2008 tentang UMKM menjelaskan definsi UMKM menggunakan nilai kekayaan bersih atau nilai aset tidak termasuk tanah dan bangunan tempat usaha atau hasil penjualan tahunan.

Tabel 2.1

Kriteria Usaha Mikro, Kecil dan Menegah Menurut UU No 20 Tahun 2008

Sumber : Kemeterian Koperasi

\section{Baitul Maal Waat Tamwil}

Dalam definisi operasional PINBUK BMT adalah kembaga ekonomi rakyat kecil beranggotakan satu orang atau badan hukum berdasarkan prinsip syariah dan prinsip koperasi, yang diharapkan menjadi lembaga pendukung kegiatan ekonomi masyarakat kecil dengan berlandaskan prinsip syariah (Rodhoni dan Hamid,
2008:60). Peran umum BMT adalah melakukan pembinaan dan pendanaan yang berdasarkan sistem syariah. Peran ini menegaskan arti penting prinsip prinsip syariah dalam kehidupan ekonomi masyarakat. Sebaga kembaga keungan syarah yang bersentuhan langsung dengan kehidupan masyarakat kecil yang serba cukup ilmu pengetahuan ataupun materi (Sudarsono, 2008:103).

Dalam opersionalnya BMT memiliki dua fungsi yakni sebagai fungsi sosial yaitu Baitul maal dan fungsi bisnis baitul tamwil (rumah pembiayaan). Dengan adanya fungsi baitul maal diwujudkan dengan melalui pengelolaan dana ZIS maupun kegiatan sosial lainnya yang berupa insentif sosial. Sedangkan fungsi baitul tamwil dengan cara menjalankan kegiatan transaksi keuangan dengan berbagai akad misalnya qardul hasan yang bisa diambil dari dana sosial, termasuk dana ZIS, pengelolaaanya dilakukan dengan prinsip syariah. Disisi lain pengelola dituntut untuk menghasilkan untung bagu penabung dan pemodal.

\section{Bank Syariah}

\begin{tabular}{|c|c|c|c|}
\hline \multirow{2}{*}{ No } & \multirow{2}{*}{ Uraian } & \multicolumn{2}{|c|}{ Kriteria } \\
\hline & & Asset & Omzet \\
\hline 1. & $\begin{array}{l}\text { Usaha } \\
\text { Mikro }\end{array}$ & $\underset{\text { Juta }}{\operatorname{Max}} 50$ & $\begin{array}{c}\text { Max } \\
300 \text { Juta }\end{array}$ \\
\hline 2. & $\begin{array}{l}\text { Usaha } \\
\text { Kecil }\end{array}$ & $\begin{array}{l}>50 \text { Juta - } \\
500 \text { Juta }\end{array}$ & $\begin{array}{l}>300 \\
\text { juta } \\
\text { M }\end{array}$ \\
\hline 3. & $\begin{array}{l}\text { Usaha } \\
\text { Mene } \\
\text { ngah }\end{array}$ & $\begin{array}{l}>500 \text { juta } \\
-10 \mathrm{M}\end{array}$ & $\begin{array}{c}>2,5 \\
M-50 M\end{array}$ \\
\hline
\end{tabular}

Sudarsono (2008:43) menjelaskan Fungsi Bank Syariah yang tercantum dalam 
AAOIFI (Accounting and Auditing Organization for Islamic Financial Institution), sebagai berikut :

a. Manajer investasi

b. Investor

c. Penyedia jasa keuangan

d. Pelaksan kegiatan sosial

Konsep operasional bank syariah adalah penghimpun dana dan penyalur dana. Bank syariah sebagai lembaga perantara keuangan juga harus melaksanakan mekanisme penghimpunan dan penyaluran dana secara seimbang, yaitu harus sesuai dengan ketentuan perbankan yang berlaku. Pada dasarnya produk yang ditawarkan bank syariah di bagi menjadi tiga bagian besar, yaitu produk penghimpunan dana (funding), Produk penyaluran dana (financing) dan Produk jasa

\section{Investasi Emas}

Investasi emas adalah salah satu bentuk investasi aset. Emas merupakan salah satu barang komoditi, karena sifatnya yang mulia, emas termasuk instrumen yang populer dan mampu dijangkau oleh investor bermodal terbatas ( Arumdati, 2011:16)

Arumdati (2011:19) mengatakan bahwa pada umumya orang memilih investasi dalam bentuk emas untuk memperoleh keuntungan dalam jangka panjang. Hal Ini disebabkan pertambahan nilai dari emas dinilai tidak terlalu besar dalam jangka pendek.

\section{Gadai Emas Bank Syariah}

Undang undang No. 7 Tahun 1992 secara eskplisit memberikan keleluasaan bagi bank syariah untuk mengembangkan sendiri produknya. Salah satu produk yang dikembangkan belakangan ini adalah gadai (rahn). Gadai Emas Syariah adalah penggadaian atau penyerahan hak penguasa secara fisik atas harta/benda berharga (berupa emas) dari nasabah (rahin) kepada bank syariah (murtahin) untuk di kelola dengan prinsip rahn yaitu sebagai jaminan (marhun) atas peminjam/utang (marhun bih) yang diberikan kepada nasbah (Anshori, 2005:129).

Dewan Syaraih Nasional Majelis Ulama Indoneisa selaku pengawas pada produk perbankan syariah mengeluarkan fatwa tentang Gadai emas. Fatwa DSN MUI No. 26/DSN-MUI/III/2002 tentang rahn emas menyebutkan bahwa :

a. Rahn emas dibolehkan berdasarkan prinsip rahn sesuai fatwa DSN MUI no. 25/DSN-MUI/III/2002

b. Ongkos dan biaya penyimpanan marhun ditanggung oleh rahin

c. Ongkos sebagaimana di maksud di poin $b$ besarnya berdasarkan pada pengeluaran nyata yang diperlukan

d. Biaya penyimpanan marhun dilakukan berdasarkan akad ijarah.

Gadai emas bank syariah yang umumnya dapat mendaptakan dana yang reltif cepat dengan proses yang mudah dan sesuai syariah, memiliki daya tarik sendiri bagi masyarakat. Biaya adminstrasi yang murah dibanding 
dengan pegadaian pada umumnya menjadi pilihan masyrakat untuk mengadaikan emas nya di Bank Syariah. Bank Syariah memberikan fasilitas tambahan dengan memberikan asuransi pada emas yang digadaikan dan emas yang digadaikan di jamin disimpan di tempat yang aman

\section{METODE PENELITIAN}

\section{Pendekatan penelitian}

Pendekatan penelitian yang digunakan dalam penelitian ini menggunakan pendekatan kualitatif. Penelitian ini bertujuan untuk mencari jawaban atas pertanyaan : "Bagaimana Gadai Emas Bank Syariah dan Baitul maal wat tamwil sebagai solusi permasalahan modal Usaha Mikro Kecil dan Menengah.?".

Strategi yang digunakan dalam peneltian ini adalah studi kasus. Menurut Yin (2009:1), Studi kasus merupakan strategi yang paling cocok bila pertanyaan suatu penilitian berkenan dengan how atau why, bila peneliti hanya memiliki sedikit peluang untuk mengontrol peristiwa peristiwa yang akan di selidiki dan bilamana fokus penelitian terletak pada fenomena kontreporer (masa kini) di dalam konteks kehidupan nyata.

\section{Ruang Lingkup Penelitian}

Ruang Lingkup penelitian terbatas memfokuskan pada produk gadai emas bank syariah -pada BRI Syariah Gubeng dan BNI Syariah KCM Rungkut dan BMT UGT Sidogiri sebagai solusi permasalahan permodalan UMKM dan mencari jawabaan bagaimana gadai emas bank syariah dan BMT menjadi solusi masalah permodalan modal UMKM.

\section{Jenis dan Sumber data}

Data yang dihimpun oleh peneliti adalah data primer (utama) dan sekunder (penunjang). Data primer adalah data yang diperoleh langsung dari sumbernya melalui wawancara dengan pihak Bank Syariah, BMT dan pengusaha UMKM. Data sekunder dari penelitian ini diperoleh dari studi kepustakaan yang memuat tentang Gadai emas bank syariah, Modal UMKM serta yang membahas UMKM

\section{Unit Analisis}

Dalam menentukan unit analisis, Peneliti menggunakan teknik purposive untuk menentukan informan dari penelitian. Dalam penelitian ini unit analisis adalah Pengusaha UMKM yang menggadaikan emasnya di BRI Syariah Gubeng, BNI Syariah KCM Rungkut dan BMT UGT Sidogori Capem Gubeng.

\section{Pengumpulan data}

Langkah langkah yang dilakukan dalam prosedur pengumpulan data adalah

1. Peneliti melakukan persiapan awal dengan mensiapkan surat dari Fakultas Ekonomi dan Bisnis Universitar Airlangga untuk izin mewawancarai

2. Peneliti melakukan wawancara kepada pihak Bank Syairah dan BMT yang berhubungan langsung dengan produlk gadai emas seputar karakteristik produk. Setelah melakukan wawancara tersebut meminta data nasabah yang melakukan 
gadai emas untuk keperluan Modal. Setelah itu penulis menwawancarai nasabah gadai emas tersebut seputar penggunaan gadai emas untuk kebutuhan modal.

\section{Teknik Keabsahan data}

Teknik triangulasi adalah teknik pemeriksaan yang memanfaatkan sesuatu yang lain. Triangulasi yang digunakan dalam penelitian ini adalah triangulasi dengan sumber. Dalam peneltian ini triangulasi sumber dilakukan dengan jalan membandingkan hasil wawancara dengan isi suatu dokumen yang berkaitan.

\section{Teknik Analisis Data}

Dalam penelitian ini, peneliti menggunakan teknik analisa penjodohan pola. Menurut Yin (2013:140) logika penjodohan pola adalah membandingkan pola yang didasarkan atas empiri dengan pola yang diprediksikan. Dalam studi kasus yang menggunakan metode deskriptif, penjodohan pola akan relevan dengan pola variabel variabel spesifik yang di prediksi dan ditentukan sebelum pengumpulan datanya.

Dari proses analisis ini semua data yang diperoleh akan diolah kembali, dihubungkan dan dibandingkan sehingga dapat diketahui masing masing bagaimana penggunaan gadai emas bank syariah dalam pemenuhan modal UMKM dan dampaknya pada perkembangan UMKM. Dengan demikian akan diketahui pula keefektifaan penggunaan gadai emas sebagai alternatif pembiayaan bank syariah dan BMT.

\section{HASIL dan PEMBAHASAN}

Untuk menjalankan aktivitasnya perniagaan atau jual beli, setiap perusahaan membutuhkan sejumlah dana, baik yang berasal dari pinjaman maupun dari modal sendiri. Dana tersebut biasanya digunakan untuk dua hal, yaitu untuk investasi dan modal kerja. Usaha Mikro Kecil dan Menengah dapat pula menambahkan modalnya dengan melakukan pinjaman.

Bank Syariah dapat menjadi jujukan pengusaha UMKM untuk mendapatkan modal. Produk Gadai Emas yang ditawarkan bank syariah dengan persayaratan yang mudah dan proses yang cepat dapat menjadi pilihan pegusaha UMKM untuk mendapatkan dana untuk pemenuhan modalnya.

Penelitian yang dilakukan di tiga tempat yaitu BRI Syariah Gubeng, BNI Syariah KCM Rungkut dan BMT UGT Sidogiri Capem Gubeng menawarkan produk ini sebagai produk pembiaayan konsumtif

Tabel 1.

Kelebihan dan Kekurangan Gadai Emas BRI Syariah, BNI Syariah KCM Rungkut dan BMT UGT Sidogiri

\begin{tabular}{|c|c|c|}
\hline Lembaga & Kelebihan & Kekurangan \\
\hline $\begin{array}{c}\text { BRI } \\
\text { Syariah } \\
\text { Gubeng }\end{array}$ & 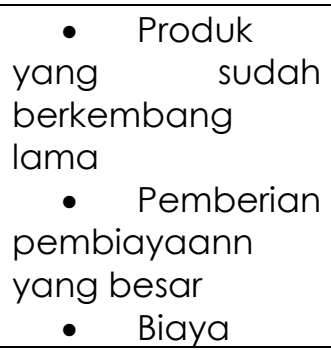 & $\begin{array}{l}\text { • Tidak } \\
\text { ada } \\
\text { pembinaan } \\
\text { untuk } \\
\text { nasabah } \\
\text { • Biaya } \\
\text { ujroh per } 10 \\
\text { harian } \\
\end{array}$ \\
\hline
\end{tabular}




\begin{tabular}{|c|c|c|}
\hline & ujroh yang murah & \\
\hline $\begin{array}{l}\quad \text { BNI } \\
\text { Syariah } \\
\text { KCM } \\
\text { Rungkut }\end{array}$ & $\begin{array}{l}\text { • Dapat } \\
\text { menambah } \\
\text { Pembiayan } \\
\text { naramh yang } \\
\text { sama } \\
\bullet \quad \text { Biaya } \\
\text { ujroh dapat } \\
\text { dihitug harian } \\
\bullet \quad \text { Apabila } \\
\text { belum lunas, } \\
\text { dapat ganti } \\
\text { nama } \\
\text { pembiayaan }\end{array}$ & $\begin{array}{l}\cdot \text { Biaya } \\
\text { ujroh yang } \\
\text { lebih mahal } \\
\bullet \quad \text { Belum } \\
\text { berkembang } \\
\text { dengan baik, } \\
\text { karena masih } \\
\text { baru }\end{array}$ \\
\hline \begin{tabular}{l}
\multicolumn{1}{c}{ BMT } \\
UGT \\
Sidogori \\
Capem \\
Gubeng
\end{tabular} & $\begin{array}{l}\bullet \text { Waktu } \\
\text { pembiayaan } \\
\text { yang fleksibel } \\
\bullet \quad \text { Jemput } \\
\text { bola anggota } \\
\bullet \quad \text { Biaya } \\
\text { ujroh dapat } \\
\text { dihitung perhari } \\
\text { • Ada } \\
\text { pembinaan untuk } \\
\text { nasabah }\end{array}$ & \begin{tabular}{l}
\multicolumn{2}{c}{ Biaya } \\
ujroh yang \\
sudah \\
termasuk \\
biaya \\
adminstrasi \\
dan biaya \\
ujroh yang \\
tinggi.
\end{tabular} \\
\hline
\end{tabular}

Darii hasil wawancara yang dilakukan

keapda informan, selaku asisten gadai BRI Syariah dan BNI Syariah, menyatakan prodk gadia emas mereka berisiko pada nasbaha yang gagal bayar, pemberian taksiran yang terlalu tinggi dan terkena barang yang palsu. Sedangkan Kepala cabang BMT UGT Sidogiri Capem Gubeng menyatakan produk gadai emas ini bebas risiko.

Kemudahan mendapatkan pembiayaan dari produk ini membuat produk ini diminati masyarakat. Hal tersebut didapatkan peneliti dari hasil pemberian kusioner terbuka terhadap pengguna gadai emas BRI Syariah. Penggunaan qardh berangun emas BRISyariah iB sebagai tambahan modal digunakan pedagang. Alasan pedagang tersebut melakukan pembiayaan gadai adalah untuk tambahan modal usahanya. Tambahan modal yang dilakukan adalah dengan membeli tambahan barang dagangan. Bertambah banyaknya barang dagangan membuat pendapatan perhari pedagang tersebut bertambah.

Tambahan modal kerja dengan menggunakan produk gadai emas dilakukan oleh Ibu Aminah yang merupakan anggota BMT UGT Sidogori Capem Gubeng. Dengan membawa emas dan tidak ada survei terlebih dahulu memudahakan ibu Aminah untuk mendapatkan tambahan modal. Kepemilikan emas menjadi alasan ibu Aminah untuk menggadaikan emas tersebut untuk mendapatkan tambahan modal usahanya. Tambahan modal tersebut digunakan untuk menambah barang dagangannya, Dengan menggunakan dana tambahan dari mengadaikan emas tersebut, Ibu Aminah sudah dapat memenuhi kebutuhannya untuk kulak barang daganganya. Bertambhanya pendapatan tersebut akan berdampak pada perkembangan usahanya.

Kemudahan mendapatkan dana untuk tambahan modal dengan menggunakan gadai emas dirasakan pula oleh lbu Maya. Ibu Maya memiliki usaha prasaman masakan Jawa Timur di dekat lokasi BNI Syariah KCM Rungkut. Sebelumnya ibu Maya sudah melakukan gadai emas di pegadaian, namun berlaih ke BNI Syariah KCM Rungkut, salah satunya dikarenakan 
menggunakan biaya ujroh bukan bunga. Tambahan modal yang dilakukan oleh Ibu Maya dengan menggunakan gadai emas adalah untuk operasional usahanya.. Dalam usahanya dengan menjual makan sudah dapat memberikan keuntungan, tetapi untuk pemenuhan kebutuhan lainnya,seperti membeli kipas angin, kulkas, ibu Maya melakukan gadia emas untuk pemenuhannya. Pembelian barang barang untuk mendukung usahanya tersebut.

Kebutuhan untuk memenuhi barang barang tersebut bersifat mendesak bagi Ibu Maya, sehingga dia lebih memilih untuk melakukan gadai emas daripada untuk membeli kredit barang tersebut ataupun harus menabung untuk membeli kebutuhnnya tersebut. Melakukan gadai emas digunakan pula sebagai alternatif ketika tidak memiliki uang tunai.

Pemenuhan kebutuhan ibu Maya yang melakukan gadai emas untuk pembelian barang elektronik untuk menambah properti usahanya kurang sesuai untuk pemenuhan kebutuhan modalnya. Pembelian barang elektronik tersebut tidak mendukung kegiatan usaha yang dilakukan ibu Maya. Tujuan ibu Maya membeli kipas angin tersebut bukan untuk mengembangkan usahanya, namun hanya untuk menambah fasilitas warung makannya. Penggunaan gadai emas sebagai modal tambahan dapat dilakukan ibu Maya untuk melakukan inovasi masakan tambahan, menambah masakan yang dijual ataupun memperbarui peralatan dapur seperti membeli kompor, oven dan piring.

Gadai emas sebagai produk penyaluran dana konsumtif untuk masyarakat dapat digunakan sebagai tambahan modal UMKM. Kesulitan UMKM mendapatkan tambahan modal untuk perkembangan usaha nya dapat dipenuhi dengan melakukan gadai emas di Bank Syariah atau BMT. Emas yang bersifat likuid menjadikan produk ini memiliki risiko yang kecil. Rahin atau nasabah yang tidak dapat melunasi pembiayaan ini, emas yang sebelumnya menjadi agunan akan dijual untuk melunasi pembiayaan sebelumnya. Keterbatasan UMKM untuk memiliki jaminan sehingga sulit untuk mendapatkan modal dapat terselesaikan dengan adanya gadai emas ini. Tambahan modal dari gadai emas ini akan mengembangkan UMKM.

\section{SIMPULAN}

Berdasarkan hasil pembahasan dapat disimpulkan bahwa produk gadai emas BRI Syariah Gubeng, BNI Syariah KCM Rungkut dan BMT UGT Sidogiri Capem Gubeng dapat menjadi solusi permasalahan permodalan UMKM. Persyaratan yang mudah dan proses yang cepat memudahkan pengusaha UMKM untuk mendapatkan tambahan modal. Pembiayaan gadai emas yang diberikan sesuai dengan kebutuhan nasabah dari nilai taksiran yang diberikan. Biaya yang dikenakan pun tidak memberatkan nasabah, sehingga gadai emas ini dapat 
menjadi alternatif UMKM untuk mendapatkan tambahan modal.

Keterbatasan modal yang sebelumnya dihadapi UMKM dapat terpenuhi dengan adanya produk gadai emas lembaga kevangan syariah. Kepemilikan emas sebagai alat investasi dan sifatnya yang likiud menjadi alasan pengusaha UMKM untuk menggadaikan emasnya. Tujuan menggadaikan emas tersebut umumnya untuk pemenuhan modal UMKM.

Karakterisitk produk yang berjangka pendek umumnya dilakukan untuk pemenuhan modal kerja. Penggunaan gadai emas selain dapat memenuhi kebutuhan modal UMKM juga dapat untuk mengembangkan dan memperbesar usaha UMKM. Tambahan modal yang dilakukan dengan menggunakan produk gadai emas selain dapat memenuhi kebutuhan mereka, juga dapat mengembangkan usaha mereka.

\section{DAFTAR PUSTAKA}

Ali, Zainduddin. 2008. Hukum Gadai Syariah. Jakarta: Sinar Grafika.

Anshori, Abdul Ghofur. 2005. Gadai Syariah di Indonesia. Yogyakarta: Gadjah Mada University Press.

Arumdati, Dewi. 2011. Cara Kaya dengan Investasi Emas:Panduan Cerdas
Berkebun Emas. Yogyakarta: Araska Publisher.

Ascaraya. 2013. Akad dan Produk Bank Syariah. Jakarta: Rajawali Pers

Departemen Koperasi dan UMKM. 2012. Perkembangan Data Usaha Mikro, Kecil, dan Menengah(UMKM) dan Usaha Besar(UB) Tahun 2011-2012. Jakarta: Kementerian Koperasi dan UMKM

Ismail. 2011. Perbankan Syariah. Jakarta: Kencana

Karim, Adiwarman A. 2004. Bank Islam Analisis figh dan keuangan. Jakarta: PT RajaGrafindo Persada

Kasmir. 2010. Pengantar Manjamen Kevangan. Jakarta: Kencana

Moleong, Lexy J. 2013. Metode penelitian Kualitatif. Bandung: PT Remaja Rosdakarya

Rais, Sasli. 2006. Pegadaian syariah, Konsep dan sistem operasional.Jakarta: UI-Press.

Rodhoni Ahmad dan Hamid Abdul. 2008. Lembaga Kevangan Syariah. Jakarta: Zikrul Hakim

Sudarsono, Heri. 2008. Bank dan Lembaga Keuangan Syariah. Yogyakarta: Ekonisia

Tambunan, Tulus. 2012. Usaha Mikro Kecil dan Menengah di Indonesia. Jakarta: LP3ES

Yin, Robert K. 2013. Studi kasus:desain dan metode. Jakarta: Rajawali Press 